\title{
obituary
}

\section{Mary Elizabeth Martin}

Formerly Consultant Psychiatrist, Rotunda Hospital, Dublin

Mary Martin will be remembered for many reasons. She was a careful, yet innovative, medical practitioner who provided a firstrate psychiatric service for women attending the Rotunda Hospital, Dublin, over the course of 35 years. The Rotunda, the oldest of Dublin's historic trio of busy maternity hospitals, initially accepted Mary's help on a voluntary basis. Her valuable work was acknowledged before long with a structured consultant appointment, the only such post in Ireland for many years. Mary published her observations on puerperal mental illness and on emotional aspects of childbearing at a time when there was little reliable work available, and her patients continued to benefit from her knowledge and concern until her retirement in 1995.

Mary grew up in Dublin. Her father, a consultant physician at the Adelaide Hospital, was from a Quaker family. Mary loved the simplicity and generosity of worship with the Friends, but also the beauty of the rituals, language and music of Anglican services. She stayed with both traditions throughout her life. Mary qualified in 1952, top of her year at Trinity College, winning scholarships from the university and her teaching hospital. In addition, she played the violin in the College orchestra. She obtained her MRCPI within 2 years, and turned at an early stage to psychiatry. She undertook her postgraduate training at St Patrick's Hospital, Dublin. Her MD was awarded in 1959 and she was elected a Foundation Member of the Royal College of Psychiatrists in 1971. Further recognition came with her election as FRCPI and FRCPsych.

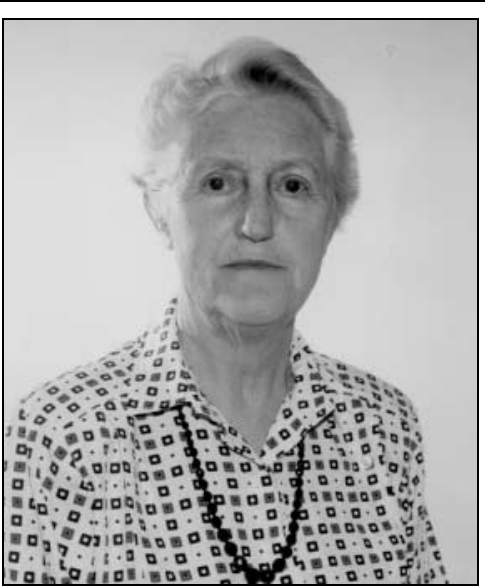

of psychiatric morbidity in pregnancy and the puerperium. In 1963 Mary published in the British Journal of Psychiatry an early controlled trial of imipramine and phenelzine in the treatment of depression. Among other articles and lectures, she wrote a fascinating account of her work at the Rotunda in a history of the hospital edited by Alan Browne. Characteristically, she praised the work of the hospital's social workers and also of the Marcé Society, acknowledging the encouragement she had received from them.

Despite her professional dedication, Mary Martin was at the centre of her family. She married Edward A. Martin, Consultant Neurologist, in 1956. She was a kind and gentle person, interested in other people, meticulous, thoughtful and orderly in all her doings, and with a ready smile. She was a fluent and prolific correspondent, writing to family and friends in longhand until very recently, when, protesting, she took to email. Eddie and Mary hosted many cheerful gatherings of friends and colleagues at their elegant house and garden in Waterloo Road. They shared wide interests, medical, historical, and artistic. Retirement enabled them to spend more time enjoying these pursuits, travelling and keeping up with the growing family. One of her six grandchildren is a medical student. Mary leaves fond and joyful memories for her immediate family, Eddie, Jane, Richard, Rachel and Christopher, and her brother Thomas Bewley, past President of the Royal College of Psychiatrists, wider family and friends.

She died on 9 November 2008.

Marcus Webb

doi: $10.1192 / p b . b p .109 .025346$ 